\title{
CARL SCHMitTIN MAAILMANVALLOITUS
}

\begin{abstract}
"Ennen ensimmäistà maailmansotaa sanoin: 'Suvereeni on se, joka päättää poikkeuksesta'. Toisen maailmansodan jälkeen elämäni ehtoona väitän: 'Suvereeni on se, joka määrää avaruuden aalloista [wer über die Wellen des Raumens verfügtl'."

- Carl Schmitt (lain. Feuerbach 1988, 401, alav. 1.)
\end{abstract}

\section{MAAILMA}

Elämää maailmassa yhteyssatelliittien ja valokaapeleiden aikana luonnehtii intiimi läheisyys. Jos "intiimisyys" ajatellaan etäisyytenä tai sen puutteena, sana viittaa sulkeumaan, aukkoon, jonka adverbin substantiaalinen käyttö on täyttänyt umpeen ja sinetöinyt. Sanan intimus latinankielinen kanta on etuliitteen in- superlatiiviaste, jolloin "intiimisyys" kääntyisi ehkä parhaiten suomeksi sanalla "sisäisin". Sanan komparatiiviaste interior on myos johdettavissa rakenteesta, jossa jokin on kiedottu toisen sisään, mutta etuliite itsessään viittaa pikemminkin suuntaan kuin sisäisyyteen. Suuntaa ilmaiseva mieli on yhä kuultavissa sanoissa kuten "invokaatio", toiselle esimerkiksi rukouksessa osoitetussa avunhuudossa. Intiimisyys olisi siten päätepiste kehityksessä, jossa etuliitteen suuntaa ilmaiseva suhde on väistynyt sisäänsä kietovan sulkeuman tieltä.

Jean-Luc Nancyn huomioiden mukaan kaiken sisäänsä sulkeva intiimisyys vastaa kokemusta maailman mielettömyydestä. "Maailmallistuminen" (mondialisation) kuvaa kokemusta maailmasta, joka kietoo kaiken; myös itsensä, sisäänsä. Maailman ulkopuolella ei ole mitään, ei edes viite- pistettä, johon nähden maailma kerran näyttäytyi mielekkäänä. Maailman ulkopuolisen katoaminen aiheuttaa - syystäkin, Nancy tuntuu varoittavan, - huolta, johon on totuttu reagoimaan kahdella tavalla. Voimme olla nihilistejä ja todeta yksioikoisesti, että sekä maailma että mieli ovat merkityksettömiä, että kumpikin on menettänyt ulkoisen viitepisteen joka sai ne kerran näyttämään "mielekkäiltä". Voimme vastata huoleen myös turvautumalla myyttiin, luomalla merkitsevän rakenteen uudestaan. Kumpikin reaktio on tutunoloinen. Nihilismissä mielettömyydestä itsestään tehdäản ulkoinen viitepiste, jolloin merkitsevä rakenne myös toistetaan, kun taas myytissä kadotettu toinen luodaan uudelleen esimerkiksi hahmona tai Gestaltina.

Mutta vaikka mielettömyyden kokemus ja sen aiheuttama huolestunut tarve toimia säilyvät ennallaan, maailma ei ole mieletön (non-sens). Sekä maailma että mieli "ovat" ( $i l y$ a) edelleen jopa filosofian tai historian väitettyjen "loppujen" jälkeen. Nancy korostaa, että huolestuttavan sulkeuman ja sen edellyttämien vastatoimien jälkeen tulevat "loput" ovat aina olleet osa modernismin perintöä:

"Maailman mieli on jo osa modernia perinnettä, jota mikään postmoderni ei oikeastaan ole lakkauttanut. Kuten kaikkien perinteiden suhteen, meidän tehtävänämme on siten tehdä siitä omamme eli toisin sanoen ohjata sitä eteenpäin, peremmälle maailmaan." (Nancy 1993, 24, alav. 1.)

Nancyn filosofian tehtävänä on siten ajatella maailma ja mieli uudella tavalla, joka ei toista merkityksen muodos- tumisen vanhaa rakennetta. Maailman ja mielen oleminen on suuntaa (être-â), olemista jollekin, johonkin, jonkun puolesta, eli toisin sanoen suhde johonkin, lahja jollekin, vastuuta jollekin, etuliitteeseen in- liittyvää suuntaa määrittelemättä päätepistettä, jota suunta kuitenkin tavoittelee (Nancy 1993, 15-19).

Maailmallistumisen ja siihen liittyvän mielettömyyden kokemuksen osalta Nancy viittaa lyhyesti myös Carl Schmittin varhaisempaan, toista maailmansotaa edeltävään tuotantoon. Schmittin käsitys politiikasta maallistuneena teologiana (PT, 53-55) on Nancyn mukaan juuri sikäli vanhan toistoa, että teoria artikuloidaan negatiivisena teologiana toistamalla teologis-poliittinen rakenne, jonka Schmitt katsoo juuri kumonneensa (Nancy 1993, 145-147). Maailmallistumisen kehitys ja tarve ratkaista siihen liittyvä mielettömyyden kokemus on kuitenkin esillä myös Schmittin myöhemmässä tuotannossa, jossa toisiaan seuraavat "tilalliset vallankumoukset" kutistavat maailmaa kullekin epookille ominaisen nomosin järjestyksen puitteissa. Alkuaineiden yksittäinen haltuun ottaminen johtaa lopulta maailman sisäänsä sulkevaan teknologiaan, joka kumoaa ihmisen järjestyneelle olemiselle välttämảttömän maan ja meren erolle perustuvan jännitteen.

Schmittin viimeinen kausi ulottuu toisen maailmansodan aatosta 1970-luvulle, ja kautta voidaan hyvällä syyllä kutsua nomosin filosofiaksi. Sille on ominaista metafyysisempi tapa lähestyä oikeutta verrattuna esimerkiksi varhaisempiin kirjoituksiin julkisoikeudesta ja 
kansainvälisestä oikeudesta. ${ }^{1}$ Schmittin filosofista kunnianhimoa luonnehtii kuitenkin ristiriitaisuus. Yhtäältä hän yhä alistaa filosofiansa oikeustieteelle ja siitä johdetuille epistemologisille ehdoille, mutta selkeänä vastakohtana tieteellisille painotuksilleen (ks. esim. NE, 5) Schmitt pyrkii myöhemmässä tuotannossaan selvittämään käsitteitä, joita hän luonnehtii "perussanoiksi" (Urwörte). Nomosin filosofia ei kuitenkaan ole: “... määrätyn filosofisen järjestelmän sanaston soveltamista oikeudellisiin kysymyksiin, vaan konkreettisten käsitteiden kehittämistä konkreettisen oikeudellisen ja yhteiskunnallisen järjestyksen immanenssista käsin" (LR, 427). ${ }^{2}$

Schmittin "väkivaltainen" tapa lukea perussanoista merkityksiä esiin ja hänen käsiterunoutensa suhde "konkreettisiin" järjestyksiin ovat antaneet monille aihetta arvioida nomosin filosofian ja Kolmannen Valtakunnan välisiä yhteyksiä. Esimerkiksi Karl Löwithin $(1984,59-60)$ mukaan schmittiläisen desisionismin viimeistä vaihetta voidaan kutsua "okkasionalistiseksi", koska poikkeustilaan tai ystävän ja vihollisen erotteluun liittyvä käsitteellinen desisionismi on siinä korvattu päätöksellä, joka koskee valtion konkreettista järjestystä ja siitä johdettua vakautta.

Mutta vaikka konkreettiset järjestykset perustetaan päätöksissä, Schmittin nomosin filosofian on välttämättä perustuttava kaikkia myöhempiä järjestyksiä edeltävään alkuperäiseen päätökseen. Nomos ei myöskään ole vakaa. Se on synergeettinen järjestys, jossa maailman alkuaineiden - etu- sijassa maan ja meren, mutta epookeille ominaisissa jatkeissaan myös ilman ja tulen - voimat ottavat yhteen jatkuvassa jännitteiden leikissä. Alkuaineiden järjestystä luonnehtii pikemminkin jännittyneisyys (Spannung) kuin vakaus. Nomos on:

“... se välitön muoto, jossa kansan [Volk] poliittinen ja yhteiskunnallinen järjestys näyttäytyy tilallisena; laidunmaan ensimmäinen mittaaminen ja jakaminen, eli toisin sanoen maan valtaus [Landnabme] ja konkreettinen järjestys, joka sekä siihen sisältyy että siitä seuraa ..." (NE, 39-40.)

\section{VALTAUS}

Tila (Raum) on siten rinnasteinen nomosin kanssa. Se näyttää viittaavan nomosin järjestyneeseen puoleen, joka ilmenee juuri eri alkuaineiden välisenä jännitteenä. Pohtiessaan tilan käsitettä Schmitt valitsee selvästi metafyysisen lähestymistavan:

"Vasta tänä päivänä määrätty ajatus on meille mahdollinen, ajatus, joka olisi mahdoton kaikkina muina aikakausina ja jonka saksalainen nykyfilosofi on artikuloinut: maailma ei ole tilassa vaan tila on maailmassa" (LM, 106). ${ }^{4}$

Mitä Heidegger, Schmittin tarkoittama "nykyfilosofi", sanoo tilasta ja maailmasta? Ihmisen oleminen on pohjimmiltaan maailmassa-olemista, joten muodollisesti se ilmenee sisällä-olemisena (In-sein). Sisällä-oleminen on olevien keskinäinen ontologinen suhde, jossa ne kukin omasta paikastaan (Ort) käsin lähestyvät toisiaan "tilassa" (Heidegger 1977, 52-59). Ihminen ilmaisee suhteensa käytettävissä oleviin työkaluihin mitätöimällä erottavan etäisyyden. Heidegger kutsuu tällaista eksistentiaalia etääntymiseksi, joka voidaan kirjaimellisesti ymmärtää etäisyyden poistamisena (Ent-fernung): ihminen tuo työkalut lähelleen jotta ne olisivat käsillä. Käsillä olemisen aste viittaa ihmisen läheisyyteen työkaluihin nähden, tai jos asia ilmaistaan toisella tavalla, käsillä olevia työkaluja luonnehtii läheisyys (Näbe) (Heidegger 1977, 104-110).

Schmitt omaksuu Heideggerilta käsityksen tilasta ja tilallisuudesta järjestyksenä, jossa ihmisen olemisen perustavat jännitteet jäsentyvät. Ihminen kirjoittautuu maailmaan ottamalla haltuun paikan alkuperäisessä valtauksessa. Schmitt ymmärtää ihmisen paikan juuri maana. Etääntyminen, tai Schmittin ilmaisua käyttäen ihmiselle ominainen tapa ottaa maailma haltuun, tapahtuu jännitteisen järjestyksen puitteissa maahan sidotun paikan ja sen ulkopuolelle jäävän vapauden välillä, maan ja meren välillä. Tilallisessa järjestyksessä maahan paikannettu ihminen lähestyy haltuun otettavissa olevaa meren alkuainetta. Maan ja meren muodostama kokonaisuus on siis tila, jossa maahan paikannetun ihmisen ja haltuun otettavissa olevan maailman välinen suhde jäsentyy olemisen perustavaa jännitettả kuvaavaksi järjestykseksi.

Tila, jossa ihmisen olemassaolo järjestyy, ei kuitenkaan ole suljettu. Raum on perustava saksankielinen sana, $U r$ wort. Foneettinen analyysi osoittaa, että diftongi "au" edustaa saksankielisten aakkosten ensimmäistä ja viimeistä vokaalia, alfaa ja omegaa, alkua ja 
loppua. Mutta alku ei pääty loppuun:

" $R$ muodostaa ... aktiivisen alun, ja $M$ on taivaanrannassa muodostuva ja sinne ulottuva loppu. Raum ei siten ole suljettu kehä tai alue vaan maailma, eikä tämä maailma ole tyhjä tila tai tyhjässä tilassa, vaan tarkoittamamme Raum on maailma jonka eri alkuaineiden väliset jännitteet täyttävät" (RR, 492493.)

Maan ja meren alkuaineista Schmitt kehittää käsityksensä nomosista paikantamisen ja järjestyksen kokonaisuutena (NE, 13-14). Ihminen on maallinen olento, joka on sidoksissa maahan kolmella eri tavalla. Kasvussaan maa suo mitan, jolla ihminen arvioi työnsä ja vaivansa suhdetta tuottoon, kun taas kynnössä tarkat rajat jakavat maan alueisiin. Lopuksi sadossaan maa antaa kiinteän perustan ykseydelle, jonka muodostavat paikantaminen (Ortung) ja järjestys (Ordnung), eli toisin sanoen nomosille. Meri edustaa sitä vastoin aluetta maan järjestyksen ulkopuolella, vapaalle kaupankäynnille ja valloituksille varattua aluetta. Mutta koska ihmisen oleminen on sidoksissa maahan, jokaisen nomosin perustana on alkuperäinen maan valtaus (ks. myös Cacciari 1985, 46-48).

Jokaisella epookilla on kuitenkin sille ominainen nomos, ja suurten merivaltojen valloitukset edustavat maan järjestyksen ulottamista merelle (Seenabme). Maan ja uusien valloitusten ja kolonisaation edustaman meren välinen suhde kuvaa ihmisen nomosin puitteisiin järjestäytyneelle olemiselle ominaista jännitettä. Niin kauan kun vapaita alueita riittää valloitettavaksi, maan ja meren perustava jän- nite säilyy. Mutta alkuperäinen maan valtaus, "suuri historiallinen tapahtuma", on arkbê (Ur-grund), jonka varassa tila ja laki käyvät alkuperäisesti yhteen paikantamisena ja järjestyksenä (NE, 15-17). ${ }^{6}$

Vähemmän metafyysisissä teksteissään Schmitt kehittelee käsitystään tilasta käsitteeksi Großraum ja teoriaksi suvereeneista valtakunnista (Reiche), jotka elävät rinnakkain rauhassa kansainvälisen oikeusjärjestyksen (Völkerrecht) puitteissa (VG, 314-320; vrt. Mehring 1989, 194-209; Kaiser 1968, 529-535). Nomosin järjestys on ehkä "epäautenttinen" sikäli että ystävällisistä ja vihamielisistä "imperiaalisista tiloista" (Großräume) muodostuvan maailman rauhanomainen vakaus perustuu taipumukseen mukautua jaetun ja merkityksellisen maailman tuttuuteen tai, Schmittin käsitteistöä lainatakseni, erinäisten poliittisten yksiköiden suvereenisuuteen.

Järjestyksenä nomos edellyttää globaalia käsitystä maailmasta, jossa alueita valtion rajojen ulkopuolella pidetään vihamielisinä. Käsitys omaksutaan vasta roomalaisessa oikeudessa sillä kreikkalaisen jus gentiumin myyttinen ja kosmopoliittinen luonne käyvät ilmi tavassa ymmärtää ulkopuoli polisin jatkeena (NE, 20). Toisin sanoen kosmos jäljittelee kreikkalaisen kaupunkivaltion rakenteellisia lakeja. Maan ja meren vastakkaisuuteen perustuva järjestys on peräisin vasta 1600 - ja 1700 lukujen kolonialistiselta aikakaudelta (NE, 24). Tätä Schmitt nimittää eurooppalaiseksi jus publicumiksi, jossa maan ja meren vastakohtaisuus edustaa nomosin jännitteisiä ja järjestyneitä luonteenpiirteitä.
Epookeille ominaisissa jatkeissaan nomosin järjestys ulotetaan lopulta globaalisesta maailmasta, jossa maan ja meren perustava ero pitää jatkuvasti yllä järjestyksen edellyttämää jännitettä, planetaariseksi maailmaksi. Planetaarinen maailma avautuu tietenkin ilmasta käsin eli toisin sanoen ottamalla haltuun ilman alkuaine. Ja lopulta tuli - 1930luvulla Schmitt liittää tulen vielä rakettimoottoriin - edustaa lopullisen tuhon mahdollisuutta teknologialle alistetussa maailmassa.

Uusissa epookeille ominaisissa nomoissa alkuaineet otetaan siten yksitellen haltuun kunnes maailma lopulta sulkeutuu itseensä, kunnes kaiken sisäänsä sulkeva olemassaolo mitätöi maan ja meren alkuperäisen eron, ihmisen maalliselle olemassaololle perustavan jännitteen. Schmittin suhde maailman sulkeutumiseen on kuitenkin epäselvä. Yhtäältä "maailmallistuminen" alkuaineiden haltuun ottamisena merkitsee vanhan eurooppalaisen jus publicumin loppua, minkä Schmitt saattaa vain pahoitellen todeta nostalgiassaan. Mutta siitä huolimatta:

"Vanha nomos vetäytyy vapaaehtoisesti, ja sen mukana vetäytyy kokonainen väliaikaisten mittojen, normien ja suhteiden järjestelmä. Mutta sitä ei kuitenkaan seuraa vain mitattomuus tai nomos-vihamielinen ei-mitään. Jopa vanhojen ja uusien katkeroituneilla alueilla syntyy oikeudenmukaisia mittoja ja perustetaan mielekkäitä suhteita." (LM, 107.)

Kaikki epookeille ominaiset nomoit perustetaan kolmivaiheisessa menettelyssä, joka vastaa Schmittin mukaan kreikankielisen verbin nemein 
kolmea ulotturuutta. Ensiksi on maan haltuun ottaminen tai valtaus (Nabme), toiseksi maan jakaminen (Teilen) ja sitä seuraava järjestys, ja lopuksi maan laiduntaminen (Weiden) eli maasta kasvavan hedelmän käyttäminen (NTW, 490-492). Schmittin ankara kritiikki oikeustieteen perinnettä kohtaan perustuu väitteeseen, että maan alkuperäinen valtaus on unohdettu kääntämällä sana nomos virheellisesti "säännöksi" tai "laiksi", järjestykseksi ilman perustaa:

“Alkuperäisessä mielessään ... nomos on täysin välittämätöntä oikeudellista voimaa, jota ei johdeta laeista; se on perustava historiallinen tapahtuma, teko jonka legitimiteetti [Legitimität] antaa pelkkien lakien legaalisuudelle [Legalität] yleisen mielekkyyden (NE, 42; vrt. LL).

Maan valtaus on päätös, joka perustaa kaikki nomoit, mutta koska epookeille ominaiset alkuaineiden haltuun ottamiset edellyttävät sekä asemaa, josta uusi valloitus pannaan täytäntöön, että vallattavaa kohdetta, toisiaan seuraavien epookkien järjestysten valtausta edeltää aina maan ja meren erolle perustuva alkuperäinen järjestys (vrt. BP, 2628). ${ }^{7}$ Ur-akte olisi siten alkuperäisen järjestyksen perustava haltuun ottaminen eli valtaus, joka paikantaa ihmisen maahan.

\section{LAHJA}

Ihmisen maalliseen olemassaoloon maan ja meren erona kuuluu siten jo tilallinen järjestys. Alkuperäisen valtauksen on tapahduttava ennen kaikkia järjestyksiä, ennen kuin valtaava (maahan paikannettu oleva) kytkee itsensä vallattavaan (meri) maallisessa olemassaolossa, eli toisin sanoen ennen kuin halun kohdetta on tunnistettu. Kuinka tällainen alkuperäinen halu voisi olla "mielekäs"? Maailmaan liittyvien suhteiden puitteissa Nancy tulkitsee mieltä halun ja lahjan välisenä jännitteenä. Jotta mieli jäisi suhteeksi, se ei voi toteutua tai mitätöityä. Halu ei voi nimetä lahjan objektia vaan jälkimmäisen on välttämättä jäätävä tuntemattomaksi sekä lahjan antajalle että sen saajalle:

"Itse lahjan [donation] ottaminen haltuun ja sen lahjoittaminen, mitä ei voida ottaa haltuun, tämä kuvastaa filosofian - ja mielen - alkuperäistä kiasmaa" (Nancy 1993, 87).

Mieli on platoninen agatbon, joka uhrataan ylivoimaisuutensa ylijäämän mukaisesti. Halu ja lahja ubrataan toisilleen, ne ovat uhrilahjoja. Uhraamisesta päättävän harkintavalta kuuluu toimijalle, joka ei voi olla haluava eikä lahjan antaja vaan ainoastaan oleva (Nancy 1993, 88). Näyttäisi kuitenkin siltä, että Schmittin nomosin filosofian alkuperäistä valtausta edeltää juuri tunnustettu lahja, sillä:

"Yksikään ihminen ei voi antaa, osittaa ja jakaa ottamatta haltuun. Vain maailman tyhjästä luova jumala voi antaa ja osittaa ottamatta haltuun." (NNN, 581.)

Kun ihminen lahjoittaa, hän jakaa jotakin joka on jo hallussa; ihminen ei voi lahjoittaa vaan ainoastaan vallata ja siirtää jakamalla eteenpäin. Mutta vallatessaan (Nabme/nebmen) ihminen myös nimeää omakseen (Name/nennen) kuten esimerkiksi maan valtauskirjassa tai asiakirjassa, jossa otetaan puoliso osoittamalla tai hyväk- symällä nimi (NNN, 583-584). Kun haltuun ottaminen tai valtaus tapahtuu omissa nimissä, siihen sisältyy välttämättä myös tunnistamista ja tunnustamista. Ihminen paikantuu maahan alkuperäisessá valtauksessa, mutta samalla maan lahja tunnustetaan saaduksi: maa "on", "se antaa" (es gibt) maan.

Näin Schmittin nomosin filosofia jää teologiseen noidankehään. Alkuperäinen maan valtaus, "suuri historiallinen tapahtuma", on myös lahja, jonka antajan jumalallisuus tunnustetaan. Ainutlaatuisessa kyvyssään luoda ex nibilo jumala paikantaa ihmisen maalliseen kotiinsa suomalla hänelle mahdollisuuden vallata sen mikä on vallattavissa. Nomosin järjestyksen perustava valtaus ei siten ole alkuperäinen päätös, jolla ihminen paikantaa itsensä maahan, vaan olemisen lahjan ja sen jumalallisen lahjoittajan tunnustamista.

Panu Minkkinen

\section{$v i$ it te e t}

1. Hofmann (1964, 198-205) on selvittanyt Schmittin viimeisen kauden historiallisia taustatekijoita.

2. Nomosista kasitteena ks. esim. Meier (1988, 552-553).

3. Myohemmin Lowith (1984, 6168) pyrkii löytamaan samanlaisen okkasionalistısen rakenteen Heideggerin ajattelusta.

4. Sama varte loytyy myos muualta (esim. VG, 319).

5. Hofmann (1964, 236-247) on vertallut poliittisemmalla tavalla Heideggerin ja Schmittin kasitteita tilasta ja tilallisuudesta (ks. myós Poschl 1965, 18-22).

6. Hegel $(1974,514-515,612$, 614) liittää maaperän (Boden) perheeseen ja meren kaupan- 
kayntiin, mutta toisin kuın Schmitt, han nakee kolonisaation valineenà (Mittel) eika perustavana valtauksena jonka avulla jảrjestys luodaan.

7. Schmittin desisionismista ja "konkreettisesta" nomosin jarjestyksesta, ks. myós Krockow (1958, 94-106).

\section{$K \perp R J A L L I S U U S$}

Carl Schmitt:

BP: Der Begriff des Polutischen Text von 1932 mit einem Vorwort und drei Corollarien Berlin. Duncker \& Humblot, 1963.

LL. Legalitat und Legitimitat Ber' lin: Duncker \& Humblot, 1988.

LM: Land und Meer. Eine weltgeschicbtliche Betracbtung Koln/Lovenich: Hohenheim, 1981.

LR. "Die Lage der europäischen Rechtswissenschaft", teoksessa Carl Schmitt, Verfassungsrechtlicbe Aufsätze aus den Jabren 1924-1954. Materialen zu einer Verfassungslebre. Berlin: Duncker \& Humblot, 1958, s. 386-429.

NE. Der Nomos der Erde im Völkerrecht des Jus Publicum Europaeum Berlin: Duncker \& Humblot, 1950.

NNN: "Nomos Nahme Name", teoksessa Carl Schmitt, Staat, Grojsraum, Nomos Arbeiten aus den Jabren 1916-1969 Berlin: Duncker \& Humblot, 1995, s. 573-591.

NTW: "Nehmen/Teilen/Weiden", teoksessa Carl Schmitt, Verfassungsrechtliche Aufsatze aus den Jabren 1924-1954 Materialen zu einer Verfassungslebre Berlin: Duncker \& Humblot, 1958, s. 489-504.

PT: Politische Theologie. Vier Kapitel zur Lebre von der Souveranität Berlin: Duncker \& Humblot, 1993.

RR: "Raum und Rom. Zur Phonetik des Wortes Raum", teoksessa Carl Schmitt, Staat, Großraum, Nomos. Arbeiten aus den Jabren 1916-1969 Berlin. Duncker \& Humblot, 1995, s 491-495

VG: "Volkerrechtliche Großraumordnung mit Interventionsverbot fur raumfremde Mächte. Ein Beitrag zum Reichsbegriff im Volkerrecht", teoksessa Carl Schmitt, Staat, Großraum, Nomos. Arbeiten aus den Jabren 1916-1969 Berlin. Duncker \& Humblot, 1995, s. 269-371

Muu kirjallisuus.

Cacciari, Massimo (1985) Icone della Legge Milano: Adelphi.

Feuerbach, Jean-Louis (1988) "La théorie du Grorßraum chez Carl Schmitt", teoksessa Helmut Quaritsch (toim.), Complexio Oppositorum. Úber Carl Schmitt. Berlin Duncker \& Humblot, s 401-424.

Hegel, G.H F (1974) Vorlesungen über Rechtsphilosophie 1818 -1831 Vierter Band. Stuttgart/ Bad Constatt. Frommann - Holzboog.

Heidegger, Martin (1977) Sern und Zett Gesamtausgabe. Band 2 Frankfurt am Main: Vittorio Klostermann.

Hofmann, Hasso (1964) Legiti- mitàt gegen Legalitàt Der Weg der politischen Pbilosophie Carl Schmitts Neuwied/Berlin. Luchterhand.

Ka1ser, Joseph H. (1968) "Europarsches Großraumdenken; Die Steigerung geschichtlicher Großen als Rechtsproblem", teoksessa Hans Barion et al (toim), Epirrbosis Festgabe für Carl Schmitt. Berlin: Duncker \& Humblot, s. 529-548

Krockow, Christian Graf von (1958) Die Entscheidung Eine Untersucbung uber Ernst Junger, Carl Scbmutt, Martin Heidegger Stuttgart. Ferdinand Enke

Lòwith, Karl (1984) "Der okkasionelle Dezisionismus von C. Schmitt", teoksessa Karl Lowith, Sämtlıche Schriften 8. Heidegger Denker in durftger Zeit Stuttgart. Carl Ernst Poeschel, s. 32-71.

Mehring, Reinhard (1989) Patbetisches Denken Carl Schmitts Denkweg am Leitfaden Hegels Katbolische Grundstellung und antimarxistische Hegelstrategie Duncker \& Humblot.

Meier, Christian (1988) "Zu Carl Schmitts Begriffsbildung Das Politische und der Nomos", teoksessa Helmut Quaritsch (toim ), Complexio Oppositorum. Über Carl Schmitt Berlin: Duncker \& Humblot, s. 537-556

Nancy, Jean-Luc (1993) Le sens du monde Paris: Galilée.

Póschl, Arnold Ernest (1965) Raum und Raumordnung Berlin: Duncker \& Humblot. 